Article

\title{
Substrate-Specific Activation of $\alpha$-Secretase by 7-Deoxy-Trans-Dihydronarciclasine Increases Non-Amyloidogenic Processing of $\beta$-Amyloid Protein Precursor
}

\author{
Yoon Sun Chun ${ }^{1,2,+}$, Yoon Young Cho ${ }^{2, \dagger}$, Oh Hoon Kwon ${ }^{2}$, Dong Zhao ${ }^{1}$, Hyun Ok Yang ${ }^{1,3, *}$ \\ and Sungkwon Chung ${ }^{2, *(1)}$ \\ 1 Natural Products Research Center, Korea Institute of Science and Technology, Gangneung 25451, Korea; \\ ysun129@skku.edu (Y.S.C.); 614003@kist.re.kr (D.Z.) \\ 2 Department of Physiology, Sungkyunkwan University School of Medicine, Suwon 16419, Korea; \\ myjubilate@hotmail.co.kr (Y.Y.C.); drummer0114@naver.com (O.H.K.) \\ 3 Division of Bio-Medical Science \& Technology, KIST School, Korea University of Science and Technology, \\ Seoul 02792, Korea \\ * Correspondence: hoyang@kist.re.kr (H.O.Y.); schung@skku.edu (S.C.); Tel.: +82-33-650-3501 (H.O.Y.); \\ +82-31-299-6103 (S.C.); Fax: +82-33-650-3529 (H.O.Y.); +82-31-299-6129 (S.C.) \\ + These authors contributed equally to this work.
}

Academic Editor: Botond Penke

Received: 7 January 2020; Accepted: 1 February 2020; Published: 3 February 2020

\begin{abstract}
Accumulation of $\beta$-amyloid $(A \beta)$ in the brain has been implicated in the pathology of Alzheimer's disease (AD). A $\beta$ is produced from the $A \beta$ precursor protein (APP) through the amyloidogenic pathway by $\beta$-, and $\gamma$-secretase. Alternatively, APP can be cleaved by $\alpha-$, and $\gamma$-secretase, precluding the production of A $\beta$. Thus, stimulating $\alpha$-secretase mediated APP processing is considered a therapeutic option not only for decreasing $\mathrm{A} \beta$ production but for increasing neuroprotective sAPP $\alpha$. We have previously reported that 7-deoxy-trans-dihydronarciclasine (E144), the active component of Lycoris chejuensis, decreases A $\beta$ production by attenuating APP level, and retarding APP maturation. It can also improve cognitive function in the AD model mouse. In this study, we further analyzed the activating effect of E144 on $\alpha$-secretase. Treatment of E144 increased $\operatorname{sAPP} \alpha$, but decreased $\beta$-secretase products from HeLa cells stably transfected with APP. E144 directly activated ADAM10 and ADAM17 in a substrate-specific manner both in cell-based and in cell-free assays. The Lineweaver-Burk plot analysis revealed that E144 enhanced the affinities of A Disintegrin and Metalloproteinases (ADAMs) towards the substrate. Consistent with this result, immunoprecipitation analysis showed that interactions of APP with ADAM10 and ADAM17 were increased by E144. Our results indicate that E144 might be a novel agent for AD treatment as a substrate-specific activator of $\alpha$-secretase.
\end{abstract}

Keywords: $\beta$-amyloid; Alzheimer's disease; $\beta$-amyloid precursor protein; $\alpha$-secretase; 7-deoxy-trans-dihydronarciclasine; Lycoris chejuensis

\section{Introduction}

Alzheimer's disease (AD) is characterized by the accumulation of extracellular senile amyloid plaques and intracellular neurofibrillary tangles composed of hyper-phosphorylated tau [1,2]. Hyperphosphorylated tau aggregates into paired helical filaments, which then form the neurofibrillary tangles and affect neurons. Thus, one strategy in AD treatment is tau-targeting [3]. Neurotoxic $\beta$-amyloid $(A \beta)$ peptides are the dominant components of senile plaques that play a central role in the 
progression of $\mathrm{AD}$. The aggregation of $\mathrm{A} \beta$ provokes neuronal dysfunction, memory impairment, and synaptic damage $[4,5]$. $A \beta$ is derived from the $A \beta$ precursor protein (APP) processed by $\beta$-secretase (BACE1) and $\gamma$-secretase. In the initial step, APP can be cleaved by $\beta$-secretase producing soluble ectodomain fragment (sAPP $\beta$ ) and C-terminal fragment (CTF), C99. C99 is further cleaved by $\gamma$-secretase to yield several A $\beta$ species with different length and APP intracellular domain (AICD). $\gamma$-Secretase complex firstly cleaves $C 99$ into longer $A \beta$ peptides, $A \beta 48$ or $A \beta 49$. Then, it further trims longer $A \beta$ peptides into a shorter variety of $A \beta$ peptides, from $A \beta 38$ to $A \beta 43$, depending on its cleavage sites [6,7]. This amyloidogenic pathway mainly releases $A \beta 40$ and $A \beta 42$. Even though $A \beta 40$ is the most abundant form, $A \beta 42$ is more prone to oligomerization and aggregation, which makes $\mathrm{A} \beta 42$ a major pathogenic factor in AD [5,6]. Alternatively, APP can be cleaved by $\alpha$-secretase within the center of the $\mathrm{A} \beta$ domain producing another soluble ectodomain fragment (sAPP $\alpha$ ) and C-terminal fragment (C83) precluding the $\mathrm{A} \beta$ generation. $\mathrm{C} 83$ is further cleaved by $\gamma$-secretase to generate $\mathrm{p} 3$ peptide and AICD. This is known as the non-amyloidogenic pathway [8,9].

Three of A Disintegrin and Metalloproteinases (ADAM) family have been suggested as potential $\alpha$-secretase: ADAM9, ADAM10, and ADAM17/tumor necrosis factor- $\alpha(\mathrm{TNF} \alpha)$ converting enzyme (TACE) $[10,11] . \alpha$-Secretase can be a constitutive cleavage enzyme or be stimulated by several G protein-coupled receptors (GPCRs) activating drugs and several kinases such as protein kinase $C$ (PKC), phosphatidyl-inositol 3-kinase, and mitogen-activated protein kinase [12,13]. Among three family members, ADAM10 is considered as sheddase for APP and other diverse cell-surface proteins, including cytokines, cell adhesion molecules (CAMs), and Notch $[13,14]$. In contrast, ADAM9 and ADAM17 are believed to undertake regulated APP cleavage $[13,15,16]$. However, several studies demonstrated that ADAM9 could mimic the constitutive function of ADAM10 in microglia cells [17,18]. In addition to APP cleavage, ADAM17 is involved in ectodomain shedding of surface-bound molecules, including TNF $\alpha$ and EGF receptor ligands as well as shedding over 80 substrates [19-22]. In addition, ADAM17 contributes to the myelination, nerite outgrowth [15] and AD-related neuroinflammation [23].

Several reports have shown that enhancing $\alpha$-secretase activity might be a potential strategy in $\mathrm{AD}$ treatment. The level of sAPP $\alpha$ in the cerebrospinal fluid of the AD patients has been found to be significantly decreased, indicating that $\alpha$-secretase activity is reduced in $\operatorname{AD}[24,25]$. Overexpression of ADAM10 decreases the formation of senile plaques but increases the secretion of sAPP $\alpha$ in an animal model of AD, while overexpression of the ADAM10 inactive mutant form increases the formation of senile plaques [26]. Mutation of ADAM10 (Q170H and R181G) has been found in AD patients [27]. Furthermore, it is reported that ADAM17-positive neurons are localized adjacent to the amyloid plaques in AD brains [28]. Overexpression of ADAM17 in HEK293 cells increased sAPP $\alpha$ release [29]. Inhibition and activation of ADAM17 regulated secretion of SAPP $\alpha$ in vitro and in vivo [30]. Thus, stimulating $\alpha$-secretase mediated APP processing is a therapeutic option for the treatment of amyloid pathology by decreasing $A \beta$ production. There have been intensive efforts to find small molecule ADAM activators, and several activators for ADAM are demonstrated [14]. However, this strategy should consider proteolysis of APP as well as various substrates, including TNF $\alpha$ and epidermal growth factor receptor ligands involved in inflammation and cancer [13]. Especially, ADAM17 participates in the shedding of diverse inflammatory factors [31]. For these reasons, a small molecule ADAM activator for AD treatment should be specific for APP sparing other substrates to avoid many deleterious consequences.

We have shown the effect of Lycoris chejuensis K. Tae et S. Ko (CJ) originated from Jeju Island in Korea on $A \beta$ generation and spatial memory ability both in vivo and in vitro [32]. Recently, we have identified 7-Deoxy-trans-dihydronarciclasine (Figure 1; coded as E144) as the active component of CJ [33]. In this study, we further examined the effect of E144 on A $\beta$ production. Acute treatment with E144 increased sAPP $\alpha$ secretion and CTF $\alpha$ level but decreased CTF $\beta$ and A $\beta$ levels. Using a cell-free assay, we found that E144 directly activated ADAM10 and ADAM17 in a substrate-specific manner. Lineweaver-Burk plot analysis revealed that E144 enhanced the affinity of ADAM17 towards its substrate. Consistent with this result, E144 increased the interaction of APP with ADAM10 and 
ADAM17. These results suggest that E144 can increase non-amyloidogenic processing of APP by activating ADAM10 and ADAM17.

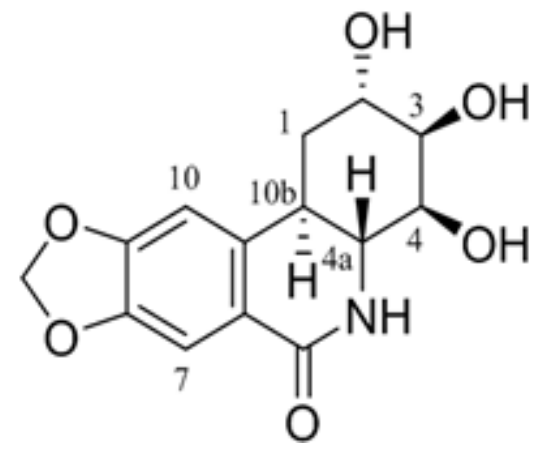

Figure 1. Chemical structure of 7-Deoxy-trans-dihydronarciclasine.

\section{Results}

\subsection{E144 Increases Secreted SAPP $\alpha$ Level but Decreases A $\beta$ Levels}

We tested the effect of E144 on sAPP $\alpha$ production from HeLa cells stably transfected with APP carrying Swedish mutation (APPsw). Cells were incubated with $1 \mu \mathrm{M}$ E144 for 1, 2, 5, or 8 h. Levels of $\operatorname{sAPP} \alpha$ in conditioned media were then measured using a specific ELISA kit (Figure 2a). When cells were incubated with E144 for $1 \mathrm{~h}$, the level of sAPP $\alpha$ was significantly increased by $29.7 \% \pm 8.4 \%$ $(n=6)$. The level of sAPP $\beta$ was decreased by E144, although the effect was not significant $(2.3 \% \pm 8.4 \%$, $n=6)$. The minimal effect of E144 on SAPP $\beta$ might be explained by the preferential APPsw cleave by $\beta$-secretase over $\alpha$-secretase [34]. These results also indicated that the effect of E144 on sAPP $\alpha$ level was not due to changed APP transport to the membrane. However, after more than $2 \mathrm{~h}$ incubation, the levels of sAPP $\alpha$ and sAPP $\beta$ were decreased by E144 in a time-dependent manner. This might be because E144 decreases APP levels, as we have previously shown using Western blots [33]. We reported that the levels of total, mature, and immature APP were decreased by E144 in a time-dependent manner. These results indicated that E144 increased the secretion of $\operatorname{sAPP} \alpha$ with $1 \mathrm{~h}$ of treatment time. We also tested the secreted level of sAPP $\alpha$ using Western blot. Cells were incubated with $1 \mu \mathrm{M}$ E144 for 1,2 , or $8 \mathrm{~h}$. Conditioned media were then concentrated and immunoprecipitated. As shown in Figure $2 b$, the level of $\operatorname{sAPP} \alpha$ was significantly increased by more than 2 -fold after $1 \mathrm{~h}$ incubation with $1 \mu \mathrm{M}$ E144 $(n=5)$. However, the level of sAPP $\alpha$ was significantly decreased at $8 \mathrm{~h}$ after incubation with E144. Apparently, the effect of E144 on SAPP $\alpha$ seemed much larger when we used the Western blot than when we used ELISA. This could be because the conditioned media were concentrated and immunoprecipitated using APP antibody for Western blot. We also tested the effects of E144 on human neuroblastoma SH-SY5Y cells, stably transfected with wild type APP. Even though A $\beta 42$ levels were too low to detect, levels of SAPP $\alpha$ in conditioned media were significantly increased by E144 after $1 \mathrm{~h}$ incubation (Supplementary Figure S1). The level of sAPP $\beta$ was not changed by E144.

We then measured levels of $\mathrm{CTF} \alpha$ and $\mathrm{CTF} \beta$, representing the products of $\alpha$ - and $\beta$-secretase, respectively. Cells were incubated with $0.5,1$, or $5 \mu \mathrm{M}$ E144 for $1 \mathrm{~h}$, and levels of CTF in cell lysates were analyzed using Western blot. A typical Western blot result is shown in Figure 2c. Relative band densities of CTF are shown in Figure 2d $(n=4)$. E144 increased the level of CTF $\alpha$ but decreased the level of CTF $\beta$. These results indicated that E144 increased non-amyloidogenic processing of APP through $\alpha$-secretase but decreased amyloidogenic processing through $\beta$-secretase. Since E144 decreased the amyloidogenic processing of APP, we examined the effect of E144 on A $\beta$ levels. Cells were incubated with $0.5,1$, or $5 \mu \mathrm{M}$ E144 for $1 \mathrm{~h}$, and levels of $\mathrm{A} \beta 42$ and $\mathrm{A} \beta 40$ in conditioned media were measured using specific ELISA kits. The level of $\mathrm{A} \beta 42$ was significantly decreased by $13.6 \% \pm 3.5 \%, 18.0 \% \pm 2.1 \%$ and $24.6 \% \pm 4 \%$ after incubation with $0.5,1$, and $5 \mu \mathrm{M}$ E144, respectively (Figure $2 \mathrm{e} ; n=4$ ). The level of 
A $\beta 40$ was also significantly reduced by $9.8 \pm 1.1 \%, 15.2 \% \pm 3.6 \%$ and $25.9 \% \pm 5.3 \%$ after incubation with $0.5,1$, and $5 \mu \mathrm{M}$ E144, respectively (Figure $2 \mathrm{f} ; n=4$ ).

a

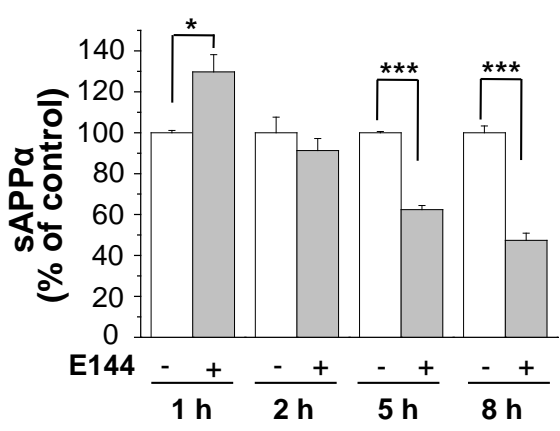

C

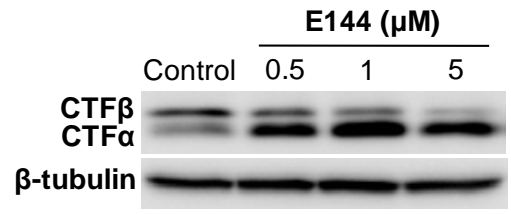

e

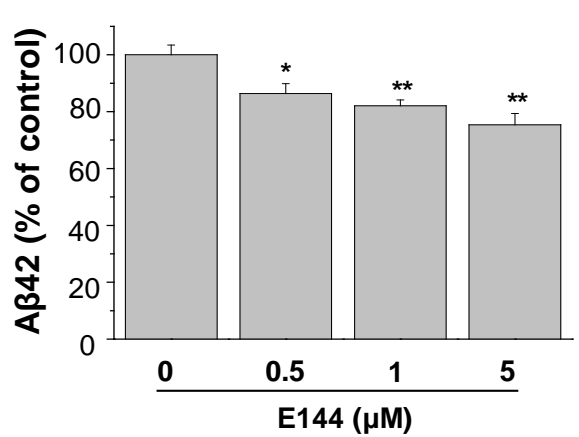

b
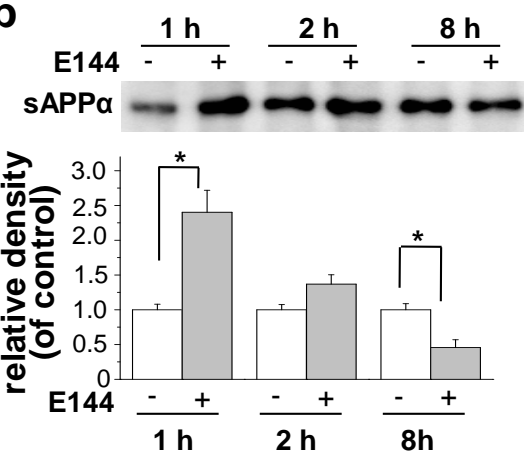

d

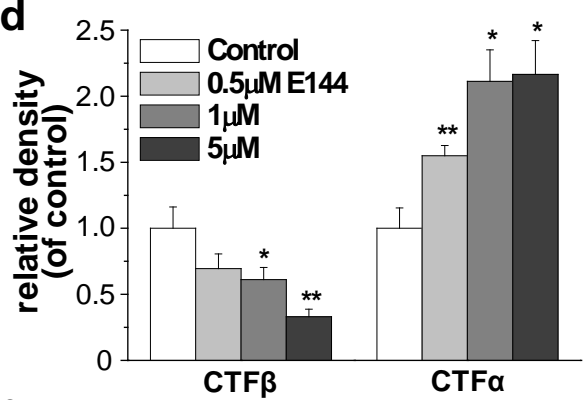

f

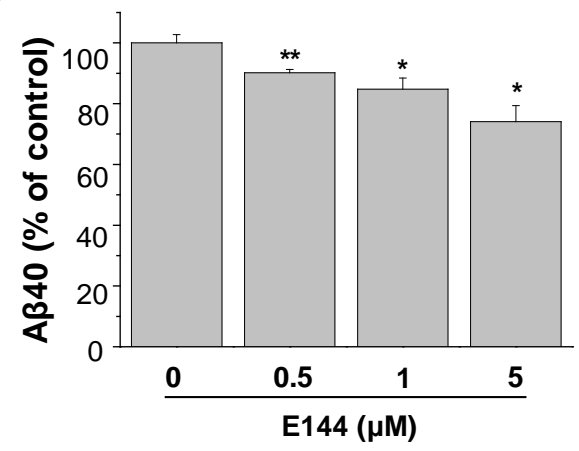

Figure 2. E144 increased the secretion of sAPP $\alpha$ and decreased A $\beta$. (a) APPsw-transfected HeLa cells were incubated with $1 \mu \mathrm{M}$ E144 for 1, 2, 5, or $8 \mathrm{~h}$. The level of SAPP $\alpha$ in conditioned media was measured using ELISA. The level of SAPP $\alpha$ was significantly increased after incubating with E144 for $1 \mathrm{~h}(n=6)$. (b) Cells were incubated with $1 \mu \mathrm{M}$ E144 for various time periods. Conditioned media were incubated with APP antibody against N-terminus, followed by immunoprecipitation with Protein G Agarose. The secreted level of SAPP $\alpha$ was detected using Western blot with the SAPP $\alpha$ antibody. E144 significantly increased the level of sAPP $\alpha$ after incubating with E144 for $1 \mathrm{~h}(n=5)$. (c) Cells were incubated with $0.5,1$, or $5 \mu \mathrm{M}$ E144 for $1 \mathrm{~h}$. The level of CTF was detected from cell lysates using Western blot analysis. $\beta$-Tubulin was used to confirm the amount of proteins loaded $(n=4)$. The full image of the Western blot is shown in Supplementary Figure S4. (d) Bars correspond to the densitometric analysis of levels of CTFs $(n=4)$. $(\mathbf{e}, \mathbf{f})$ Cells were incubated with E144 for $1 \mathrm{~h}$. Levels of $\mathrm{A} \beta 42$ and $\mathrm{A} \beta 40$ in conditioned media were measured using ELISA. E144 decreased both $\mathrm{A} \beta 42$ and A $\beta 40$ levels in a dose-dependent manner $(n=4) .{ }^{*} p<0.05 ;{ }^{* *} p<0.01 ;{ }^{* * *} p<0.001$.

\subsection{E144 Directly Activates ADAM17}

Since E144 increased non-amyloidogenic processing of APP by $\alpha$-secretase, we investigated whether E144 affected $\alpha$-secretase activity. First, we performed a cell-based assay for ADAM17 activity using APPsw-transfected HeLa cells. The cell lysate was added into an anti-human ADAM17-coated 
plate and incubated for $1 \mathrm{~h}$ to capture ADAM17. Then, Mca-KPLGL-Dpa-AR, a fluorogenic ADAM17 substrate, was added and incubated for an additional $5 \mathrm{~h}$ with $0.1,0.5,1$, or $5 \mu \mathrm{M}$ E144. Fluorescence of the quenched substrate was directly related to the enzyme activity. TAPI-1, an ADAM17 inhibitor, inhibited the activity of ADAM17 by $83.1 \%(n=6)$, confirming that ADAM17 activity could be measured from cell lysates (Figure 3a). E144 at 0.5, and $1 \mu \mathrm{M}$ significantly increased ADAM17 activity by $32.1 \%$ and $70.8 \%$, respectively $(n=6)$. ADAM17 activity was increased by more than 4 -fold after incubation with $5 \mu \mathrm{M}$ E144. Thus, E144 activated ADAM17 in a concentration-dependent manner. We also performed a cell-free assay for ADAM17 activity using human recombinant ADAM17. E144 increased the activity of human recombinant ADAM17, as shown in Figure $3 \mathrm{~b}(n=4)$. ADAM17 activity was markedly increased by 2 -fold after incubation with $5 \mu \mathrm{M}$ E144. This result using recombinant ADAM17 in a cell-free environment suggested that E144 directly activated ADAM17.
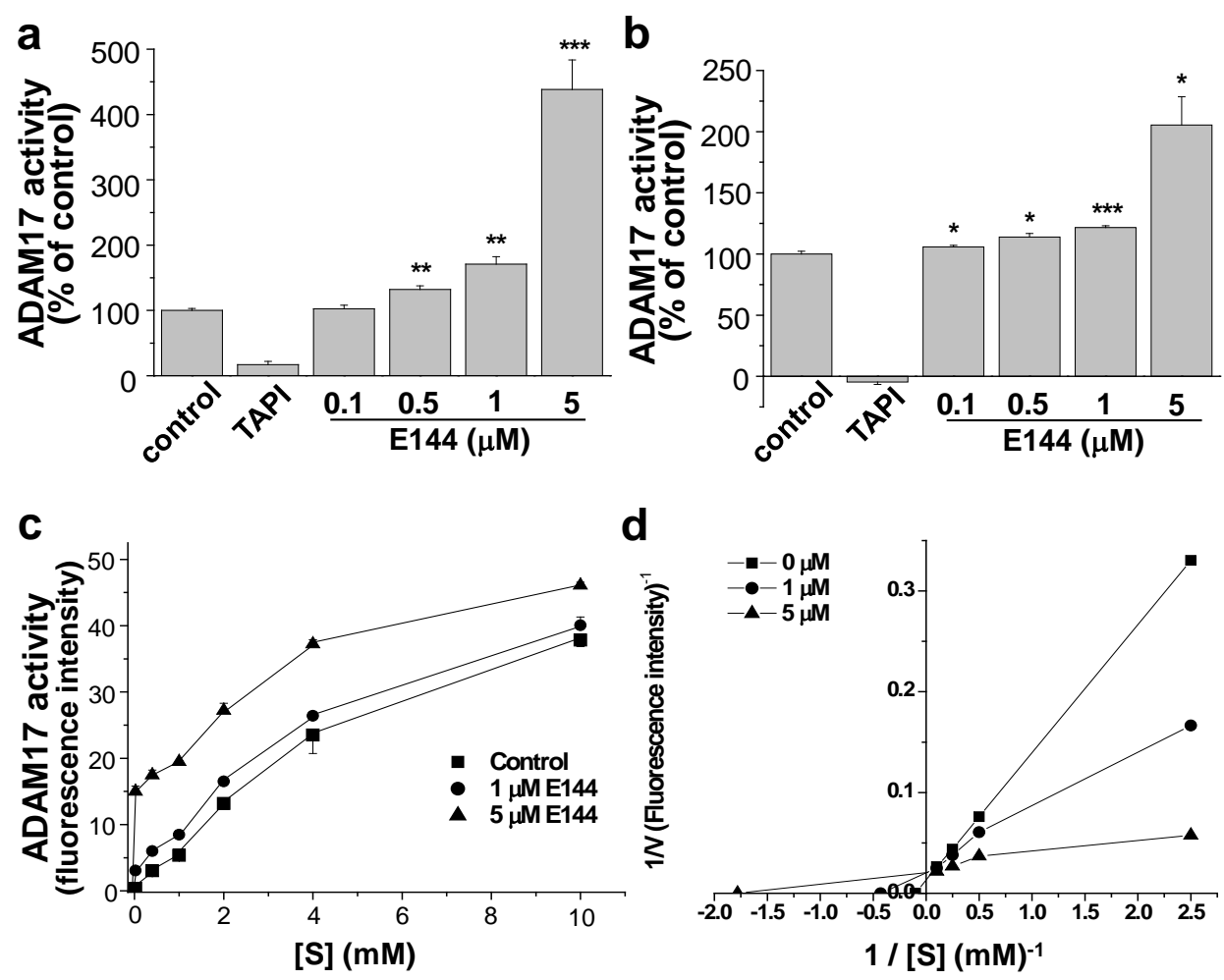

Figure 3. E144 activated A Disintegrin and Metalloproteinase (ADAM)17. (a) E144 activated ADAM17 in a cell-based assay. APPsw-transfected HeLa cell lysate was used to measure ADAM17 activity as described in the Materials and Methods. A fluorogenic ADAM17 substrate, Mca-KPLGL-Dpa-AR, was incubated in the presence of $0.1,0.5,1$, or $5 \mu \mathrm{M}$ E144 $(n=6)$. ADAM17 activity was inhibited by $50 \mu \mathrm{M}$ TAPI-1. (b) E144 increased ADAM17 activity in a cell-free assay. Human recombinant ADAM17 was used to measure ADAM17 activity in the presence of $0.1,0.5,1$, or $5 \mu \mathrm{M}$ E144 $(n=4)$. TAPI- 1 at $50 \mu \mathrm{M}$ inhibited ADAM17 activity. (c,d) Human recombinant ADAM17 (200 ng/mL) was incubated with 0.02, $0.4,1,2,4$, or $10 \mathrm{mM}$ substrate in the presence $(1$ or $5 \mu \mathrm{M})$ or absence of E144 $(n=4)$. After incubation at $37^{\circ} \mathrm{C}$ for $5 \mathrm{~h}$, fluorescence was measured. Plots of $1 / \mathrm{V}$ versus $1 /[\mathrm{S}]$ were fitted by Lineweaver-Burk plot analysis. ${ }^{*} p<0.05 ;{ }^{* *} p<0.01 ;{ }^{* * *} p<0.001$.

E144 at 1 or $5 \mu \mathrm{M}$ E144 increased the activity of human recombinant ADAM17 in a time-dependent manner when we used a fluorogenic ADAM17 substrate (Supplementary Figure S2). We then tested whether the activating effect of E144 on ADAM17 was blockable by the presence of an ADAM17 inhibitor. Even in the presence of TAPI-1, E144 was able to activate ADAM17 with similar potency as in the absence of TAPI-1 (Supplementary Figure S3). Thus, the activating effect of E144 on ADAM17 was independent of TAPI-1, the known inhibitor of ADAM17. 
We examined the substrate-dependent effects of 1 or $5 \mu \mathrm{M}$ E144, as shown in Figure 3c. Human recombinant ADAM17 was incubated with 0.02, 0.4, 1, 2, 4, or 10 mM Mca-KPLGL-Dpa-AR. Lineweaver-Burk plot analysis was conducted to define the effect of E144 on ADAM17-catalyzed reaction (Figure $3 \mathrm{~d} ; n=4$ ). When the fluorescence intensities were plotted on the $\mathrm{X}$-axis, and the substrate concentrations were plotted on the Y-axis, they showed different slopes that intersected together at an identical point. The $\mathrm{V}_{\max }$ of the enzyme was $26.2 \mathrm{mM} / \mathrm{min}$ and $\mathrm{K}_{\mathrm{m}}$ was $0.02 \mathrm{mM}$ in the presence of $5 \mu \mathrm{M}$ E144, compared with the $\mathrm{V}_{\max }$ of $11.4 \mathrm{mM} / \mathrm{min}$ and $\mathrm{K}_{\mathrm{m}}$ of $0.58 \mathrm{mM}$ for the control. Thus, E144 decreased Michaelis-Menten constant $\mathrm{K}_{\mathrm{m}}$ while maximal velocity, $\mathrm{V}_{\max }$, was apparently not or moderately affected.

\subsection{E144 Activates ADAM17 in a Substrate-Specific Manner}

It is known that ADAM17 mediates the cleavage of the substrates involved in brain pathology, inflammation, and cancer [35]. $\mathrm{TNF} \alpha$, one of the cardinal pro-inflammatory cytokines, is a well-known substrate for ADAM17 [20,21]. Thus, activation of ADAM17 by E144 might increase TNF $\alpha$ secretion and lead to an inflammatory reaction. To test this possibility, we measured secreted levels of TNF $\alpha$ from microglial BV-2 cells. The secreted TNF $\alpha$ level without lipopolysaccharide (LPS) stimulation in these cells was undetectable with the ELISA method. Thus, cells were pre-incubated with $1 \mu \mathrm{g} / \mathrm{mL}$ LPS for $3 \mathrm{~h}$, and the culture medium was exchanged with a fresh one. Cells were then treated with 0.5 or 1 $\mu \mathrm{M}$ E144 in the presence of LPS for an additional $1 \mathrm{~h}$. TNF $\alpha$ levels in conditioned media were measured using a specific ELISA kit (Figure 4a). The secretion of TNF $\alpha$ was significantly increased by stimulation with LPS. However, the presence of $1 \mu \mathrm{M}$ E144 decreased LPS-induced TNF $\alpha$ level by $14.7 \%(n=5)$. These results indicated that while E144 activated ADAM17 towards APP and a fluorescent substrate, Mca-KPLGL-Dpa-AR, it also inhibited ADAM17 towards another substrate, thereby reducing the secreted TNF $\alpha$. To clarify this substrate-specific activating effect of E144 on ADAM17, we measured ADAM17 activity using another fluorogenic ADAM17 substrate, QXL520/5-FAM. TAPI-1, an ADAM17 inhibitor, inhibited the activity of human recombinant ADAM17 (Figure $4 b ; n=5$ ). When recombinant ADAM17 was incubated with 1 or $5 \mu \mathrm{M}$ E144 for $40 \mathrm{~min}$, ADAM17 activity did not change. Considering these results, the activating effect of E144 was specific for certain substrates.

a

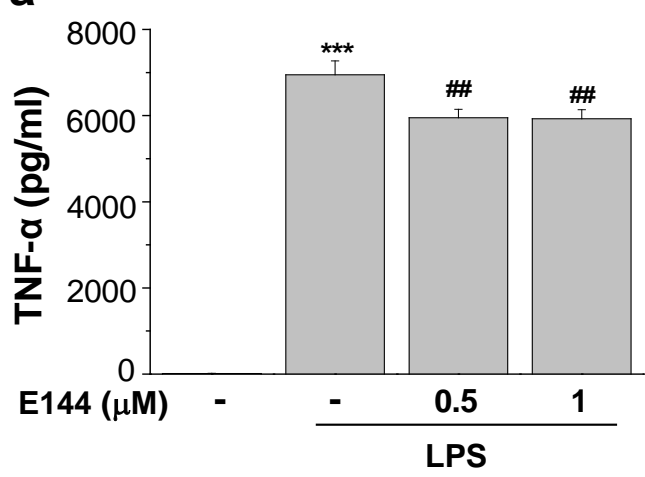

b

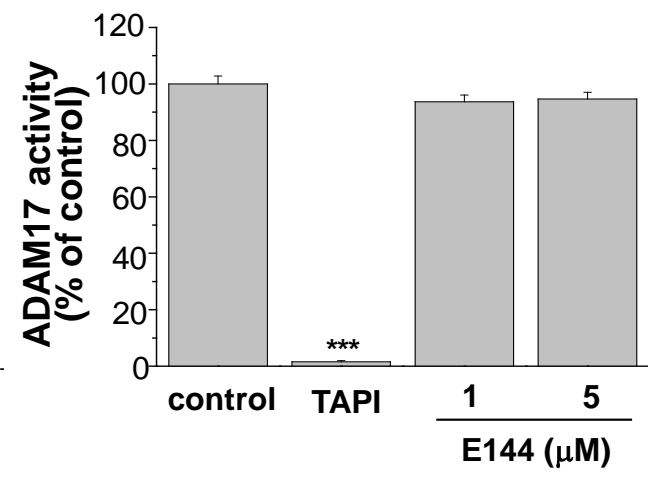

Figure 4. E144 activated ADAM17 in a substrate-specific manner. (a) BV-2 cells were incubated with $1 \mu \mathrm{g} / \mathrm{mL}$ LPS for $3 \mathrm{~h}$, and the culture medium was exchanged with a fresh one. Cells were then treated with 0.5 or $1 \mu \mathrm{M}$ E144 in the presence of LPS for $1 \mathrm{~h}$. Levels of TNF $\alpha$ were measured in conditioned media using ELISA $(n=5)$. (b) ADAM17 activity was measured using an assay kit. Human recombinant ADAM17 was incubated for 40 min with 1 or $5 \mu \mathrm{M}$ E144 in the presence of ADAM17 substrate, QXL520/5-FAM $(n=5)$. TAPI-1 at $50 \mu \mathrm{M}$ inhibited ADAM17 activity. ${ }^{* * *} p<0.001$ compared to the control group; ${ }^{\# \#} p<0.01$ compared to LPS-induced control group. 


\subsection{E144 Activates ADAM10 in a Substrate-Specific Manner}

We next tested the effect of E144 on ADAM10 activity in both a cell-based and cell-free assay. For the cell-based assay, ADAM10 from the lysate of APPsw-transfected HeLa cells was incubated with 1 or $5 \mu \mathrm{M}$ E144 for $40 \mathrm{~min}$ in the presence of the ADAM10 substrate, 5-FAM/QXL520. Fluorescence of the quenched substrate was directly related to the enzyme activity. ADAM10 activity did not change by 1 and $5 \mu \mathrm{M}$ of E144 (Figure $5 \mathrm{a}, n=4$ ). E144 did not affect human recombinant ADAM10 in a cell-free activity assay either (Figure $5 b, n=4$ ). The inhibitor of ADAM10, GM-6001, inhibited ADAM10 activity by $80 \%$. We next tested the effect of E144 on human recombinant ADAM10 activity using another substrate, Mca-KPLGL-Dpa-AR, the same substrate used in Figure 3a,b for the ADAM17 activity assay. GM-6001 inhibited the activity of ADAM10 by 35\% (Figure 5c). When ADAM10 was incubated with Mca-KPLGL-Dpa-AR for $1 \mathrm{~h}$, E144 activated ADAM10 activity in a concentration-dependent manner. E144 at $5 \mu \mathrm{M}$ concentration significantly increased ADAM10 activity by $27.9 \%(n=4)$. These results indicated that E144 could activate ADAM10 and ADAM17 in a substrate-specific manner. However, the activating effect of E144 on ADAM10 was less potent than that on ADAM17 although we used the same substrate, Mca-KPLGL-Dpa-AR.
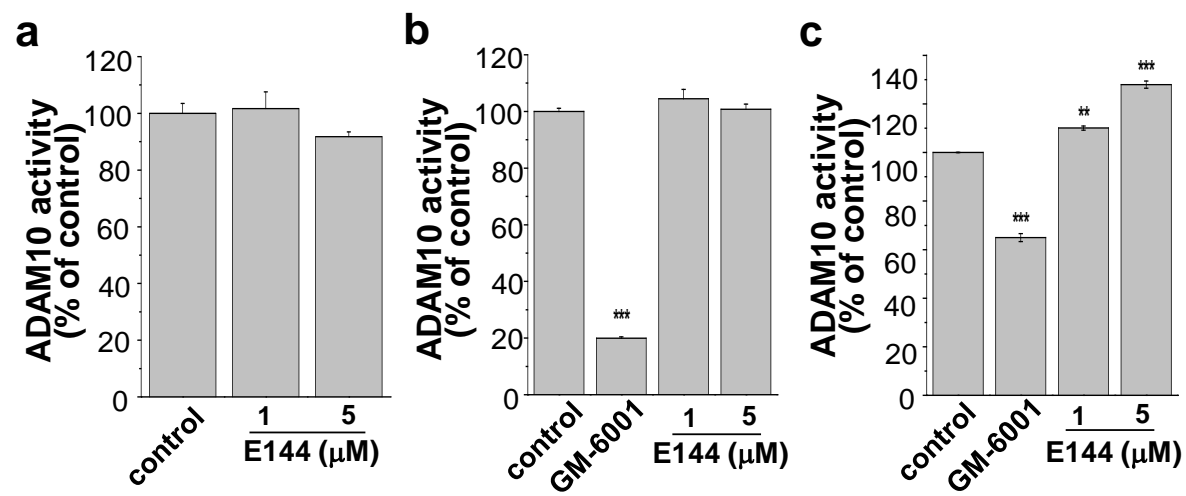

Figure 5. E144 also activated ADAM10 in a substrate-specific manner. (a) E144 did not affect ADAM10 activity in the cell-based assay. Lysate of APPsw-transfected HeLa cells was incubated for 40 min with 1 or $5 \mu \mathrm{M}$ E144 in the presence of ADAM10 substrate, 5-FAM/QXL520 $(n=4)$. (b) E144 did not affect ADAM10 activity in a cell-free assay using human recombinant ADAM10 $(n=4)$. (c) ADAM10 activity was measured using substrate, Mca-KPLGL-Dpa-AR. Human recombinant ADAM10 was incubated with 1 or $5 \mu \mathrm{M}$ E144 for $1 \mathrm{~h}(n=4) .{ }^{* *} p<0.01$; ${ }^{* * *} p<0.001$.

ADAM10 is the major physiological $\alpha$-secretase mediating the cleavage of APP in the neurons. In contrast, ADAM9 and ADAM17 participate in a regulated cleavage of APP [15]. Since we observed that the activating effect of E144 on ADAM17 was more potent than that on ADAM10, we tried to identify the target of E144 in physiological condition with intact cells. We used specific siRNAs for ADAM9, 10, and 17. As shown in Figure 6a, we were able to reduce expression levels of these proteins by more than $90 \%$ using specific siRNAs. When ADAM9 or ADAM10 was down-regulated, E144 was able to decrease $\mathrm{A} \beta 42$ levels similar to control siRNA-treated cells (Figure $6 \mathrm{~b} ; n=6$ ). In contrast, the effect of E144 was completely prevented when ADAM17 was down-regulated. These results suggest that the effect of E144 on A $\beta$ might be mostly via ADAM17 in intact cells. 
a
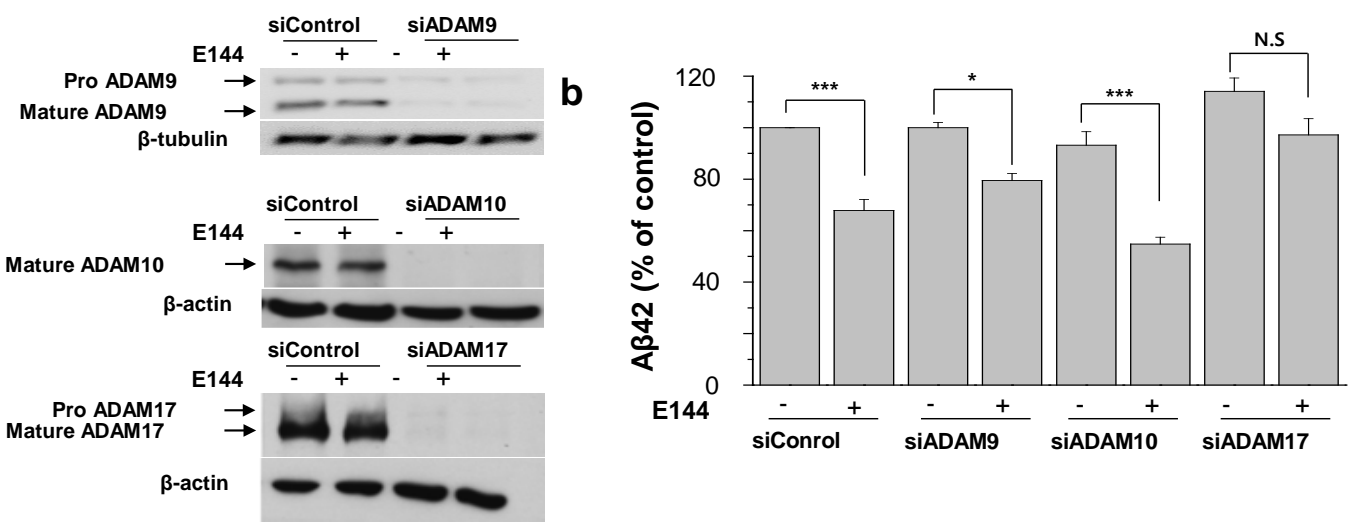

Figure 6. Suppression of ADAM17 expression prevented the effect of E144 on A $\beta 42$ production. APPsw-transfected HeLa cells were treated either with siControl or with siRNA against ADAM9, ADAM10, ADAM17 for $72 \mathrm{~h}$. (a) Representative Western blot image showed that the expressions of all three enzymes were suppressed by over $90 \%$ in our experimental siRNA conditions $(n=6)$. $\beta$-Tubulin and $\beta$-actin were used as loading controls. Full images of Western blot are shown in Supplementary Figure S5. (b) At $72 \mathrm{~h}$ post-siRNA ADAMs, cells were washed and incubated with $1 \mu \mathrm{M}$ E144 for $1 \mathrm{~h}$. Levels of A $\beta 42$ in the conditioned media were analyzed using specific ELISA $(n=6)$. Left bars are without E144 in the presence of different siRNAs. ${ }^{*} p<0.05 ;{ }^{* * *} p<0.001$.s

\subsection{E144 Increases Interaction of APP with ADAM10 and ADAM17}

We showed that E144 directly activated ADAM10 and ADAM17 using recombinant enzymes. We also showed that E144 enhanced the affinity ADAM17 towards the substrate. In addition, APP can bind to the $\alpha$-/ $\beta$-secretase binary complex [36]. Thus, we tested the effect of E144 on the interaction of APP with ADAM10 and ADAM17 (ADAMs) by performing co-immunoprecipitation analysis in APPsw-transfected HeLa cells. Cells were treated with 1 or $5 \mu \mathrm{M}$ E144 for $1 \mathrm{~h}$ followed by immunoprecipitation of cell lysate with APP antibody and probing for ADAMs using Western blot. A typical result is shown in the upper panel of Figure 7a. Relative band densities of immunoprecipitated ADAM9, ADAM10, and ADAM17 are shown in Figure 7b $(n=4)$. E144 did not affect the interaction between APP and ADAM9. In contrast, E144 increased both APP-ADAM10 and APP-ADAM17 interactions. We next measured the expression level of ADAMs. Cells were treated with 1 or $5 \mu \mathrm{M}$ E144 for $1 \mathrm{~h}$. Levels of ADAMs in cell lysates were then analyzed using Western blot. A typical Western blot result is shown in the lower panel of Figure 7a. The relative band densities of ADAMs compared to $\beta$-tubulin are shown in Figure 7c $(n=4)$. ADAMs exist as a pro-enzyme in the trans-Golgi network and undergo maturation through removal of pro-domain, thereby converting to a mature, active form of the enzymes [37]. Levels of both precursor and active ADAM9 were significantly decreased by 5 $\mu \mathrm{M}$ E144. However, levels of ADAM10 or ADAM17 were not significantly changed by E144. These results indicate that activating effects of E144 on ADAM10 and ADAM17 might be due to increased interaction between APP and ADAMs by E144.

\subsection{Differential Effects of Structural Analogues of E144 on ADAM10 and ADAM17}

Previously, we have confirmed that three active components of CJ, E144, Narciclasine (E2), and 7-Deoxynarciclasine (E3), can decrease the production of A $\beta$ by attenuating APP levels [32]. Since E2 and E3 were structural analogs of E144, we tested whether E2 and E3 could affect the activities of ADAM10 and ADAM17. When human recombinant ADAM10 was used, E2 increased ADAM10 activity like E144 (Figure 8a). However, E3 did not change the ADAM10 activity. Similarly, E2, but not E3, increased ADAM17 activity when we used cell lysates (Figure 8b). Thus, structural analogs of E144 showed differential effects on ADAM10 and ADAM17 activities. 


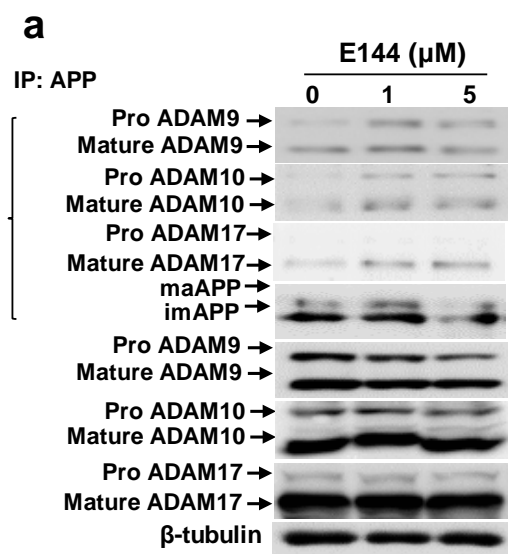

b

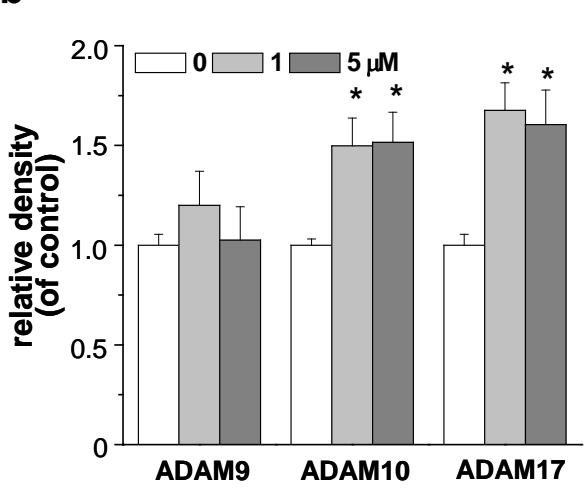

C

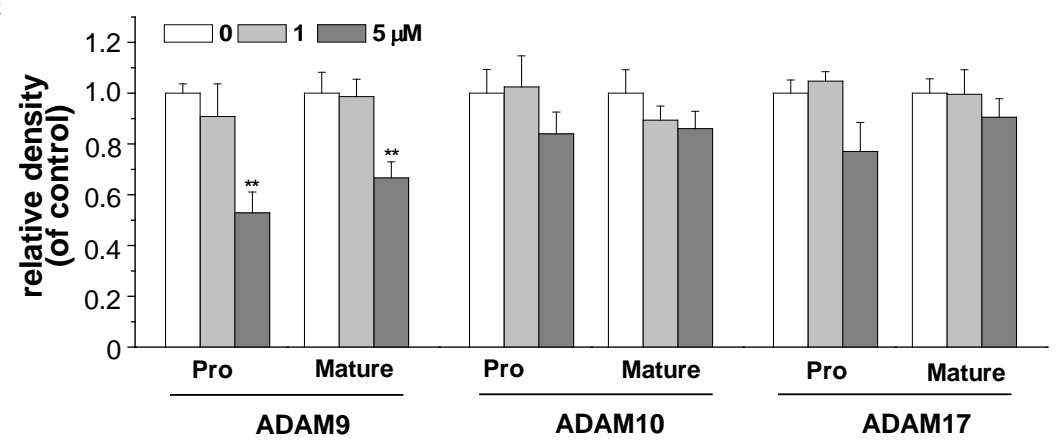

Figure 7. E144 increased the interaction between APP and ADAMs. APPsw-transfected HeLa cells were incubated with indicated concentrations of E144 for $1 \mathrm{~h}$. (a) Upper panel (IP). Cell lysates were co-immunoprecipitated with APP antibody, followed by Western blot with ADAM9, ADAM10, ADAM17, and APP antibodies. Lower panel. Cell lysates were obtained to detect the expression level of ADAM9, ADAM10, and ADAM17. $\beta$-Tubulin was used to confirm the amount of proteins loaded. Full images of Western blot are shown in Supplementary Figure S6. (b) Densitometric analysis of Western bands in the upper panel (IP) in (a) $(n=4)$. (c) ADAM9, ADAM10, and ADAM17 levels were quantified by performing densitometric analysis of bands in the lower panel in $(\mathbf{a})(n=4)$. ${ }^{*} p<0.05 ;{ }^{* *}, p<0.01$.
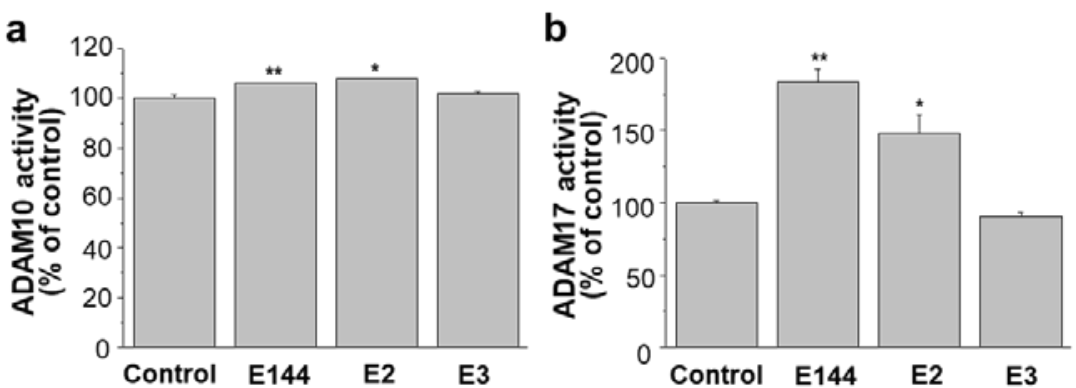

Figure 8. E2 also increases ADAM10 and ADAM17 activities. (a) Human recombinant ADAM10 was incubated for $1 \mathrm{~h}$ with substrate, Mca-KPLGL-Dpa-AR. The presence of $1 \mu \mathrm{M}$ E144 and Narciclasine (E2) increased ADAM10 activity $(n=3)$. The presence of 7-Deoxynarciclasine (E3) was without effect. (b) APP-transfected HeLa cell lysate was used to measure ADAM17 activity as described in the Materials and Methods. A fluorogenic ADAM17 substrate was incubated in the presence of $1 \mu \mathrm{M}$ E144, E2, and E3. ADAM17 activity was significantly activated by $1 \mu \mathrm{M}$ E144 and E2 $(n=4) .{ }^{*} p<0.05 ;{ }^{* *}, p<0.01$.

\section{Discussion}

We have recently reported that E144 can attenuate the secretion of $A \beta$ through decreasing the APP level and delaying the maturation of APP [33]. Notably, chronic treatment with E144 significantly 
decreased levels A $\beta$ and APP in brains of Tg2576 mice, an APP transgenic mouse model of AD. E144 also rescued behavioral deficits in TG mice. In the present study, we further found that acute treatment with E144 caused direct activation of $\alpha$-secretase in HeLa cells transfected with APPsw. Consequently, E144 promoted the non-amyloidogenic processing of APP, thereby increasing levels of sAPP $\alpha$ and CTF $\alpha$ while decreasing levels of CTF $\beta$ and A $\beta$. E144 mostly decreased $K_{m}$ of ADAM17. This may indicate that E144 enhances the affinity of ADAM17 towards its substrates. It is possible that E144 can modulate interactions between $\alpha$-secretase and APP, affecting APP cleavage and A $\beta$ generation. Consistent with this result, E144 increased the interaction of APP with ADAM10 and ADAM17 when we performed co-immunoprecipitation analysis. E2, a structural analog of E144, also increased ADAM10 and ADAL17 activities. Interestingly, however, another analog, E3, did not change the activities of these enzymes.

One strategy for AD therapeutics is stimulating $\alpha$-secretase to inhibit the amyloidogenic processing of APP. $\operatorname{sAP} \alpha$, a product from APP by $\alpha$-secretase, has been shown to be beneficial for memory function, to have neuroprotective properties, and to be able to stabilize neuronal calcium homeostasis [38-42]. We found that E144 had a beneficial effect in upregulating the secretion of SAPP $\alpha$ by acute treatment. However, the level of sAPP $\alpha$ was decreased by E144 in a time-dependent manner at more than $2 \mathrm{~h}$ after treatment. This event is likely to be attributable to the decrease in APP level by E144 [33]. Our data using fluorogenic peptide substrates showed that E144 directly activated ADAM17 in a cell-free assay. In addition, we showed that E144 was a substrate-specific ADAM17 activator. Even though fluorogenic peptides used in our experiments were designed to reduce the cross-reactivities between ADAMs, further studies using full-length cellular substrates will be needed to confirm the substrate-specificity of E144. In addition, further experiments are needed to elucidate how E144 activates ADAM10 and ADAM17 in a substrate-specific manner.

ADAM proteins can cleave various substrates, including TNF- $\alpha$, an epidermal growth factor involved in inflammation and cancer $[43,44]$. Recent studies have implicated that activation of $\alpha$-secretase can induce unfavorable effects because ADAM proteins can increase the processing of other substrates, resulting in the promotion of tumorigenesis, tumor growth, and inflammation [13]. Thus, the importance of substrate-specific ADAM targeting has been highlighted in the AD research field to avoid side-effect [14]. Our data showed that E144 decreased the secreted level of TNF- $\alpha$, ruling out the possibility that E144 might cause putative side-effects by increasing TNF- $\alpha$. Instead, E144 significantly decreased LPS-induced TNF $\alpha$ level, consistent with a recent report regarding the anti-inflammatory effect of E144 [45]. These results indicated that while E144 activated ADAM17 towards certain substrate such as Mca-KPLGL-Dpa-AR, it also inhibited ADAM17 towards another substrate, thereby reducing the secreted TNF $\alpha$.

Some natural compounds, also extracted from plants, have been studied to activate $\alpha$-secretase for treating AD. Resveratrol, a natural polyphenolic flavonoid extracted from several plants such as grapes, has neuroprotective and antioxidant properties [46]. It can also promote the level of ADAM10 expression, which may induce an increase of CTF $\alpha$ level in APP-transfected CHO cells [47]. Curcumin isolated from the plant Curcuma longa has antioxidant and anti-inflammatory properties [48]. Curcumin amino-acids conjugates with isoleucine, phenylalanine, or valine enhance the expression level of ADAM10 and secretion of sAPP $\alpha$ [49]. In line with that, a recent study revealed that melatonin enhanced non-amyloidogenic processing inhibited $A \beta$ aggregation and amyloid plaques via increasing ADAM10 expression and its activity [14]. Retinoic acid was also suggested as a transcriptional activator for ADAM10 increasing ADAM10 expression, consequently decreasing A $\beta$ production [50]. Furthermore, it has been reported that acitretin, a second-generation retinoid, enhances the up-regulation of $\alpha$-cleavage processing of APP accompanying the increase of sAPP $\alpha$ levels in human patient CSF [51]. Importantly, the study of Brummer and colleagues showed that acitretin has the substrate-specific ADAM10 activating effect [52].

Our results indicated that E144 and E2, natural compounds isolated from the plant, could be used as a potential agent for the treatment of AD by activating ADAM10 and ADAM17 in a substrate-specific 
manner. However, further experiments have to include various substrates of ADAM10 and ADAM17 to avoid many deleterious consequences by activating these enzymes. Moreover, additional experiments are needed to clearly show that the major target of E144 is ADAM17 over ADAM10 since it has been reported that ADAM17-mediated alpha cleavage of APP, referred to as the "regulated" pathway, is mostly occurring when PKC is stimulated $[13,15,16]$. Since activation of GPCR can increase APP processing by $\alpha$-secretase via ADAM17 [13], the effect of E144 on ADAM17 may occur through GPCR signaling. It is also possible that the components present in the cell enhance the action of E144, increasing the affinity of ADAM17 toward its substrate. This may also explain why recombinant ADAM17 exhibited a lower level of activation by E144 (Figure 3a versus Figure 3b). Several binding partners of ADAM17 have been identified to enhance ADAM17 activity. Thioredoxin-1 is involved in the regulation of ADAM17 activity as a partner of the ADAM17 cytoplasmic domain in HEK293 cells [53]. The scaffolding protein synapse associated protein 97 as a binding partner of the cytoplasmic domain of TACE in mammalian cells regulates TACE shedding activity [54]. Thus, binding partners and scaffolding protein of ADAM17 could increase the action of E144, enhancing the affinity between ADAM17 and its substrate in the cellular environment.

\section{Materials and Methods}

\subsection{Cell Culture and Experimental Treatments}

HeLa cells stably transfected with an APP carrying Swedish mutation (APPsw) were cultured at $37^{\circ} \mathrm{C}$ with $5 \% \mathrm{CO}_{2}$. Dulbecco's Modified Eagle Medium (DMEM) was used with $10 \%$ heat-inactivated fetal bovine serum (FBS) containing 100 units/mL penicillin, $100 \mu \mathrm{g} / \mathrm{mL}$ streptomycin, $260 \mu \mathrm{g} / \mathrm{mL}$ Zeocin, and $400 \mu \mathrm{g} / \mathrm{mL}$ G418. BV-2 microglia cells were cultured at $37^{\circ} \mathrm{C}$ with $5 \% \mathrm{CO}_{2}$ in F12/DMEM (1:1) with $10 \%$ FBS, 100 units $/ \mathrm{mL}$ penicillin, and $100 \mu \mathrm{g} / \mathrm{mL}$ streptomycin. LPS (Sigma, 62326, St. Louis, $\mathrm{MO}, \mathrm{USA}$ ) was dissolved in water.

\section{2. sAPP $\alpha$ Immunoprecipitation}

APPsw-transfected HeLa cells were incubated with $6 \mathrm{~mL}$ culture media containing DMSO or E144 at a density of $5 \times 10^{6}$ cells in $100 \mathrm{~mm}$ dish. Two $100 \mathrm{~mm}$ dishes were prepared for each condition. Conditioned media of $12 \mathrm{~mL}$ volume for each condition were collected and concentrated to $100 \mu \mathrm{L}$ using a kit (Millipore, ACK5030GS). Concentrated media were immunoprecipitated with Protein G Agarose (Millipore). APP antibody against N-terminus (Abcam, Cambridge, UK) was used. For the Western blot, immunoprecipitated samples were washed 3 times with PBS and probed for SAPP $\alpha$ (Covance, Princeton, NJ, USA).

\subsection{Protein Extraction and Western Blotting}

APPsw-transfected HeLa cells were washed with PBS and homogenized using lysis buffer (100 $\mathrm{mM} \mathrm{NaCl}, 1 \%$ Triton X-100,1 mM sodium orthovanadate, protease inhibitors, $50 \mathrm{mM}$ HEPES, $\mathrm{pH}$ 7.2). Centrifugation of cell lysates was carried out at $10,000 \times g$ for $10 \mathrm{~min}$. The Bradford assay (Bio-Rad, Hercules, CA, USA) was used to measure protein concentration in the supernatant. SDS-PAGE ( $8 \%$ or $15 \%$ ) was used to resolve proteins. The resolved proteins were transferred to a polyvinylidene fluoride membrane. Then, it was blocked using nonfat milk powder (5\%) in Tris-buffered saline/Tween 20 (TBST) for $1 \mathrm{~h}$ at room temperature. The membrane was then incubated overnight at $4{ }^{\circ} \mathrm{C}$ with anti-sAPP $\alpha$ (Covance), anti-CTF (Sigma), anti-ADAM9 (Cell Signaling Technology, Danvers, MA, USA), anti-ADAM10 (Abcam), anti-ADAM17 (Abcam), anti- $\beta$-tubulin (Sigma), or $\beta$-actin (EnoGene, New York, USA). After washing membranes using TBST, horseradish peroxidase-conjugated goat anti-mouse IgG or goat anti-rabbit IgG (Cell Signaling Technology) were incubated at room temperature for $1 \mathrm{~h}$. Enhanced chemiluminescence was performed to visualize the peroxidase activity. Multi Gauge Software (Fujifilm, Tokyo, Japan) using a LAS-4000 system was used to quantify the detected signals. 


\section{4. sAPP $\alpha$ and A Peptide Assay}

APPsw-transfected HeLa cells were treated with chemicals dissolved in DMSO. Specific ELISAs were used to measure levels of sAPP $\alpha$ (IBL), A $\beta 42$ (Invitrogen, Carlsbad, CA, USA), and A $\beta 40$ (Invitrogen) from conditioned medium according to the supplier's instructions.

\subsection{TNFa Assay}

BV-2 cells were treated with $1 \mu \mathrm{g} / \mathrm{mL}$ LPS (Sigma) for $3 \mathrm{~h}$ and then cultured with E144 for $1 \mathrm{~h}$ at 37 ${ }^{\circ} \mathrm{C}$. The cultured medium was collected, and the level of TNF $\alpha$ was measured using specific ELISA (R\&D Systems) according to the supplier's instruction.

\section{6. $\alpha$-Secretase Activity Assay}

To measure ADAM17 activity for a cell-based assay using the TACE activity kit (Calbiochem, CBA042, San Diego, CA, USA), APPsw-transfected HeLa cells were collected and centrifuged at 700 $g$ for $5 \mathrm{~min}$. After washing with PBS, cells were suspended in extraction buffer (Novagen, Madison, WI, USA) at a final density of $2 \times 10^{7}$ cells $/ \mathrm{mL}$. Lysates were incubated on ice for $30 \mathrm{~min}$ and centrifuged at $10,000 \times g$ for $5 \mathrm{~min}$. The supernatant was diluted 1:1 with a sample buffer. TAPI-1 (Calbiochem) was dissolved in DMSO. TACE activity was then measured according to the supplier's instructions using a fluorogenic ADAM17 substrate, Mca-KPLGL-Dpa-AR- $\mathrm{NH}_{2}$. After incubation at $37^{\circ} \mathrm{C}$ for $5 \mathrm{~h}$, fluorescence was measured at an excitation wavelength of $320 \mathrm{~nm}$ and an emission wavelength of 400 $\mathrm{nm}$. Human recombinant ADAM17 was used to measure ADAM17 activity for a cell-free assay. It was diluted with sample buffer to yield a final concentration of $200 \mathrm{ng} / \mathrm{mL}$. The Lineweaver-Burk plot was obtained using a fluorogenic ADAM17 substrate and recombinant ADAM17. Recombinant ADAM17 was incubated with a ADAM17 substrate at $0.02,0.4,1,2,4$, or $10 \mathrm{mM}$ in the presence or absence of E144. The change in fluorescence intensity was plotted on the Y-axis, and substrate concentration was plotted on the X-axis. ADAM17 activity was also measured using another TACE activity kit (AnaSpec, AS-72085, Fremont, CA, USA). Recombinant ADAM17 (200 ng/mL) was incubated with a different fluorogenic ADAM17 substrate, QXL520/5-FAM, in the presence or absence of E144. Fluorescence intensity was measured at an excitation wavelength of $490 \mathrm{~nm}$ and an emission wavelength of $520 \mathrm{~nm}$.

To measure ADAM10 activity for a cell-based assay, cells were collected and washed with PBS. Next, cells were suspended in cold assay buffer at a final density of $8 \times 10^{6}$ cells $/ \mathrm{mL}$. Lysates were incubated on ice for $30 \mathrm{~min}$ and centrifuged at 10,000 $\mathrm{g}$ for $5 \mathrm{~min}$. ADAM10 activity from the supernatant was analyzed using a kit (AnaSpec, AS-72226) and the substrate, FAM/QXL520, according to the supplier's instructions. Human recombinant ADAM10 was used for a cell-free assay. It was diluted with an assay buffer to yield a final concentration of $250 \mathrm{ng} / \mathrm{mL}$. The substrate was incubated in the presence of E144 for $40 \mathrm{~min}$ at $37^{\circ} \mathrm{C}$. Fluorescence was measured at an excitation wavelength of 490 $\mathrm{nm}$ and an emission wavelength of $520 \mathrm{~nm}$. The relative fluorescence intensity units were calculated compared to the control.

\section{7. siRNA-Mediated Knockdown of ADAM9, ADAM10, and ADAM17}

Specific siRNA oligonucleotides against ADAM9, ADAM10, and ADAM17 were designed as follows: ADAM9, 5'-GCTGGGAGGCTCTTCCTCTTCATCCTT-3', ADAM10, 5'-CGTACACACAATAAACCTT-3, and ADAM17, 5' -AACAAATCTCCAAAGTGGCTCTATGTT-3' Negative control oligonucleotides (SN-1001) were purchased from Bioneer (Oakland, CA, USA).

To knockdown ADAMs, the APPsw-transfected HeLa cells were pre-incubated in a serum-free medium without antibiotics for $1 \mathrm{~h}$, followed by incubation in serum- and antibiotic-free medium with $20 \mathrm{nM}$ siRNA duplexes using Lipofectamine 2000 (Invitrogen) according to the manufacturer's instruction. After $4 \mathrm{~h}, \mathrm{FBS}$ was added to make $10 \% \mathrm{FBS}$ in medium $(v / v)$. At $24 \mathrm{~h}$ post-siRNA treatment, antibiotic-free media with $10 \mathrm{nM}$ siRNA duplexes using Lipofectamine 2000 were added and incubated for an additional $48 \mathrm{~h}$. 
To determine the effects of E144 on ADAMs, cells were washed with pre-warmed PBS to remove siRNA duplexes after $72 \mathrm{~h}$ of treatment with siRNAs. Cells were then incubated with complete medium containing $1 \mu \mathrm{M}$ E144. At $1 \mathrm{~h}$ post-treatment with E144, cells were harvested with APP lysis buffer (50 mM HEPES, pH 7.2, $100 \mathrm{mM} \mathrm{NaCl}, 1 \%$ Triton X-100, and $1 \mathrm{mM}$ sodium orthovanadate, and protease inhibitors). The supernatant was stored at $-20^{\circ} \mathrm{C}$ until measuring levels of secreted $\mathrm{A} \beta 42$ using Human A $\beta 42$ ELISA High sensitivity Kit (Millipore, Burlington, VT, USA). The same amount of proteins from total lysates was subjected to Western blot analysis to determine the efficiency of siRNA mediated knockdown of ADAMs.

\subsection{Co-Immunoprecipitation}

APPsw-transfected HeLa cells were incubated with E144 for $1 \mathrm{~h}$ at $37^{\circ} \mathrm{C}$. Cells were washed with PBS and homogenized using a lysis buffer. Cell lysates were centrifuged at 10,000 $\mathrm{g}$ for $10 \mathrm{~min}$ at $4{ }^{\circ} \mathrm{C}$. Then, the supernatant was collected. Total proteins $(300 \mu \mathrm{g})$ were incubated with $2 \mu \mathrm{L}$ antibody directed against APP (6E10; Covance) for $2 \mathrm{~h}$. Immunoprecipitated proteins were washed 3 times with PBS. Western blot was then performed for analysis.

\subsection{Statistical Analysis}

Mean \pm SEM was used to express all data. Statistical comparisons between controls and treated experimental groups were analyzed using Student's $t$-test. $p<0.05$ was considered statistically significant.

Supplementary Materials: The following are available online. Figure S1: E144 increased the secretion of SAPP $\alpha$ and decreased A $\beta$ from SH-SY5Y cells stably transfected with wild type APP, Figure S2: E144 increases ADAM17 activity in a time-dependent manner, Figure S3: The effect of E144 on ADAM17 activation is not abolished by a ADAM17 inhibitor, TAPI-1, Figure S4: Full image of Western blotting for Figure 2c: Figure S5: Full image of Western blotting for Figure 6a: Figure S6: Full image of Western blotting for Figure 7a.

Author Contributions: S.C. and H.O.Y., designed the study. Y.S.C. and Y.Y.C., performed cell cultures, A $\beta$ assays, and statistical analyses. O.H.K. and D.Z., performed the Western blot and TNF $\alpha$ assay. S.C. and Y.Y.C., wrote the manuscript with critical evaluation and comment from Y.Y.C., O.H.K., H.O.Y. All authors have read and agreed to the published version of the manuscript.

Funding: This work was funded and supported by the Bio-Synergy Research Project (NRF-2012M3A9C4048793) and the Bio \& Medical Technology Development Program (NRF-2015M3A9A5030735) funded by the Ministry of Science, ICT, and Future Planning through the National Research Foundation, Republic of Korea to H.O.Y. This work was also supported by Basic Science Research Program through the National Research Foundation of Korea (NRF) funded by the Ministry of Education, Science and Technology (2016R1D1A1A09919505) to S.C.

Conflicts of Interest: The authors declare no conflict of interest.

\section{References}

1. Selkoe, D.J. Alzheimer's disease: Genes, proteins, and therapy. Physiol. Rev. 2001, 81, 741-766. [CrossRef] [PubMed]

2. Tanzi, R.E.; Bertram, L. Twenty Years of the Alzheimer's Disease Amyloid Hypothesis: A Genetic Perspective. Cell 2005, 120, 545-555. [CrossRef]

3. Congdon, E.E.; Sigurdsson, E.M. Tau-targeting therapies for Alzheimer disease. Nat. Rev. Neurol. 2018, 14, 399-415. [CrossRef]

4. Hardy, J.; Selkoe, D.J. The amyloid hypothesis of Alzheimer's disease: Progress and problems on the road to therapeutics. Science 2002, 297, 353-356. [CrossRef] [PubMed]

5. Mattson, M.P. Pathways towards and away from Alzheimer's disease. Nature 2004, 430, 631-639. [CrossRef] [PubMed]

6. Suzuki, N.; Cheung, T.; Cai, X.; Odaka, A.; Otvos, L.; Eckman, C.; Golde, T.; Younkin, S. An increased percentage of long amyloid $\beta$ protein secreted by familial amyloid $\beta$ protein precursor ( $\beta$ APP717) mutants. Science 1994, 264, 1336-1340. [CrossRef] 
7. Fernandez, M.A.; Klutkowski, J.A.; Freret, T.; Wolfe, M.S. Alzheimer Presenilin-1 Mutations Dramatically Reduce Trimming of Long Amyloid $\beta$-Peptides $(\mathrm{A} \beta)$ by $\gamma$-Secretase to Increase 42-to-40-Residue A $\beta$. J. Boil. Chem. 2014, 289, 31043-31052. [CrossRef]

8. Thinakaran, G.; Koo, E.H. Amyloid precursor protein trafficking, processing, and function. J. Boil. Chem. 2008, 283, 29615-29619. [CrossRef]

9. Gandy, S. The role of cerebral amyloid $\beta$ accumulation in common forms of Alzheimer disease. J. Clin. Investig. 2005, 115, 1121-1129.

10. Lammich, S.; Kojro, E.; Postina, R.; Gilbert, S.; Pfeiffer, R.; Jasionowski, M.; Haass, C.; Fahrenholz, F. Constitutive and regulated $\alpha$-secretase cleavage of Alzheimer's amyloid precursor protein by a disintegrin metalloprotease. Proc. Natl. Acad. Sci. USA 1999, 96, 3922-3927. [CrossRef]

11. Buxbaum, J.D.; Liu, K.N.; Luo, Y.; Slack, J.L.; Stocking, K.L.; Peschon, J.J.; Johnson, R.S.; Castner, B.J.; Cerretti, D.P.; Black, R.A. Evidence that tumor necrosis factor alpha converting enzyme is involved in regulated alpha-secretase cleavage of the Alzheimer amyloid protein precursor. J. Boil. Chem. 1998, 273, 27765-27767. [CrossRef] [PubMed]

12. Sannerud, R.; Annaert, W. Trafficking, a key player in regulated intramembrane proteolysis. Semin. Cell Dev. Boil. 2009, 20, 183-190. [CrossRef] [PubMed]

13. Postina, R. Activation of $\alpha$-secretase cleavage. J. Neurochem. 2011, 120, 46-54. [CrossRef] [PubMed]

14. Peron, R.; Vatanabe, I.P.; Manzine, P.R.; Camins, A.; Cominetti, M.R. Alpha-Secretase ADAM10 Regulation: Insights into Alzheimer's Disease Treatment. Pharmaceuticals 2018, 11, 12. [CrossRef]

15. Kuhn, P.H.; Wang, H.; Dislich, B.; Colombo, A.; Zeitschel, U.; Ellwart, J.W.; Kremmer, E.; Rossner, S.; Lichtenthaler, S.F. ADAM10 is the physiologically relevant, constitutive alpha-secretase of the amyloid precursor protein in primary neurons. EMBO J. 2010, 29, 3020-3032. [CrossRef]

16. Hsia, H.-E.; Tüshaus, J.; Brummer, T.; Zheng, Y.; Scilabra, S.D.; Lichtenthaler, S.F. Functions of 'A disintegrin and metalloproteases (ADAMs)' in the mammalian nervous system. Cell. Mol. Life Sci. 2019, 76, 3055-3081. [CrossRef]

17. Cissé, M.A.; Sunyach, C.; Lefranc-Jullien, S.; Postina, R.; Vincent, B.; Checler, F. The Disintegrin ADAM9 Indirectly Contributes to the Physiological Processing of Cellular Prion by Modulating ADAM10 Activity. J. Boil. Chem. 2005, 280, 40624-40631. [CrossRef]

18. Cissé, M.; Braun, U.; Leitges, M.; Fisher, A.; Pagès, G.; Checler, F.; Vincent, B. ERK1-independent $\alpha$-secretase cut of $\beta$-amyloid precursor protein via M1 muscarinic receptors and PKC $\alpha / \varepsilon$. Mol. Cell. Neurosci. 2011, 47, 223-232. [CrossRef]

19. Edwards, D.; Handsley, M.; Pennington, C. The ADAM metalloproteinases. Mol. Asp. Med. 2008, 29, $258-289$. [CrossRef]

20. Black, R.A.; Rauch, C.T.; Kozlosky, C.J.; Peschon, J.J.; Slack, J.L.; Wolfson, M.F.; Castner, B.J.; Stocking, K.L.; Reddy, P.; Srinivasan, S.; et al. A metalloproteinase disintegrin that releases tumour-necrosis factor- $\alpha$ from cells. Nature 1997, 385, 729-733. [CrossRef]

21. Moss, M.L.; Jin, S.-L.C.; Milla, M.E.; Burkhart, W.; Carter, H.L.; Chen, W.-J.; Clay, W.C.; Didsbury, J.R.; Hassler, D.; Hoffman, C.R.; et al. Cloning of a disintegrin metalloproteinase that processes precursor tumour-necrosis factor- $\alpha$. Nature 1997, 385, 733-736. [CrossRef]

22. Blobel, C.P. ADAMs: key components in EGFR signalling and development. Nat. Rev. Mol. Cell Boil. 2005, 6, 32-43. [CrossRef] [PubMed]

23. Wei, Z.; Yu, D.; Bi, Y.; Cao, Y. A disintegrin and metalloprotease 17 promotes microglial cell survival via epidermal growth factor receptor signalling following spinal cord injury. Mol. Med. Rep. 2015, 12, 63-70. [CrossRef] [PubMed]

24. Sennvik, K.; Fastbom, J.; Blomberg, M.; Wahlund, L.-O.; Winblad, B.; Benedikz, E. Levels of $\alpha$ - and $\beta$-secretase cleaved amyloid precursor protein in the cerebrospinal fluid of Alzheimer's disease patients. Neurosci. Lett. 2000, 278, 169-172. [CrossRef]

25. Lannfelt, L.; Basun, H.; Wahlund, L.-O.; Rowe, B.A.; Wagner, S.L. Decreased $\alpha$-secretase-cleaved amyloid precursor protein as a diagnostic marker for Alzheimer's diseas. Nat. Med. 1995, 1, 829-832. [CrossRef]

26. Postina, R.; Schroeder, A.; Dewachter, I.; Bohl, J.; Schmitt, U.; Kojro, E.; Prinzen, C.; Endres, K.; Hiemke, C.; Blessing, M.; et al. A disintegrin-metalloproteinase prevents amyloid plaque formation and hippocampal defects in an Alzheimer disease mouse model. J. Clin. Investig. 2004, 113, 1456-1464. [CrossRef] 
27. Kim, M.; Suh, J.; Romano, N.; Truong, M.H.; Mullin, K.; Hooli, B.; Norton, D.; Tesco, G.; Elliott, K.; Wagner, S.L.; et al. Potential late-onset Alzheimer's disease-associated mutations in the ADAM10 gene attenuate $\alpha$-secretase activity. Hum. Mol. Genet. 2009, 18, 3987-3996. [CrossRef]

28. Skovronsky, D.M.; Fath, S.; Lee, V.M.; Milla, M.E. Neuronal localization of the TNF $\alpha$ converting enzyme (TACE) in brain tissue and its correlation to amyloid plaques. J. Neurobiol. 2001, 49, 40-46. [CrossRef]

29. Slack, B.E.; Ma, L.K.; Seah, C.C. Constitutive shedding of the amyloid precursor protein ectodomain is up-regulated by tumour necrosis factor- $\alpha$ converting enzyme. Biochem. J. 2001, 357, 787-794. [CrossRef]

30. Merlos-Suárez, A.; Fernández-Larrea, J.; Reddy, P.; Baselga, J.; Arribas, J. Pro-tumor necrosis factor- $\alpha$ processing activity is tightly controlled by a component that does not affect notch processing. J. Boil. Chem. 1998, 273, 24955-24962. [CrossRef]

31. Qian, M.; Shen, X.; Wang, H. The Distinct Role of ADAM17 in APP Proteolysis and Microglial Activation Related to Alzheimer's Disease. Cell. Mol. Neurobiol. 2015, 36, 471-482. [CrossRef] [PubMed]

32. Kim, J.; Park, Y.; Chun, Y.S.; Cha, J.W.; Kwon, H.C.; Oh, M.S.; Chung, S.; Yang, H.O. Effect of Lycoris chejuensis and its active components on experimental models of Alzheimer's disease. J. Agric. Food Chem. 2015, 63, 6979-6988. [CrossRef] [PubMed]

33. Chun, Y.S.; Zhang, L.; Li, H.; Park, Y.; Chung, S.; Yang, H.O. 7-Deoxy-trans-dihydronarciclasine Reduces $\beta$-Amyloid and Ameliorates Memory Impairment in a Transgenic Model of Alzheimer's Disease. Mol. Neurobiol. 2018, 55, 8953-8964. [CrossRef] [PubMed]

34. Citron, M.; Oltersdorf, T.; Haass, C.; McConlogue, L.; Hung, A.Y.; Seubert, P.; Vigo-Pelfrey, C.; Lieberburg, I.; Selkoe, D.J. Mutation of the $\beta$-amyloid precursor protein in familial Alzheimer's disease increases $\beta$-protein production. Nature 1992, 360, 672-674. [CrossRef] [PubMed]

35. Pruessmeyer, J.; Ludwig, A. The good, the bad and the ugly substrates for ADAM10 and ADAM17 in brain pathology, inflammation and cancer. Semin. Cell Dev. Boil. 2009, 20, 164-174. [CrossRef] [PubMed]

36. Wang, X.; Pei, G. Visualization of Alzheimer's Disease Related $\alpha-/ \beta-/ \gamma$-Secretase Ternary Complex by Bimolecular Fluorescence Complementation Based Fluorescence Resonance Energy Transfer. Front. Mol. Neurosci. 2018, 11, 431. [CrossRef]

37. Seals, D.F.; Courtneidge, S.A. The ADAMs family of metalloproteases: multidomain proteins with multiple functions. Genes Dev. 2003, 17,7-30. [CrossRef]

38. Mattson, M.P. Cellular actions of $\beta$-amyloid precursor protein and its soluble and fibrillogenic derivatives. Physiol. Rev. 1997, 77, 1081-1132. [CrossRef]

39. Kögel, N.; Deller, T.; Behl, C. Roles of amyloid precursor protein family members in neuroprotection, stress signaling and aging. Exp. Brain Res. 2011, 217, 471-479. [CrossRef]

40. Guo, Q.; Robinson, N.; Mattson, M.P. Secreted $\beta$-amyloid precursor protein counteracts the proapoptotic action of mutant presenilin-1 by activation of NF-kappaB and stabilization of calcium homeostasis. J. Boil. Chem. 1998, 273, 12341-12351. [CrossRef]

41. Isacson, O. Alzheimer's disease and Down's syndrome: roles of APP, trophic factors and ACh. Trends Neurosci. 2002, 25, 79-84. [CrossRef]

42. Postina, R. A Closer Look at $\alpha$-Secretase. Curr. Alzheimer Res. 2008, 5, 179-186. [CrossRef] [PubMed]

43. Arduise, C.; Abache, T.; Li, L.; Billard, M.; Chabanon, A.; Ludwig, A.; Mauduit, P.; Boucheix, C.; Rubinstein, E.; Le Naour, F. Tetraspanins regulate ADAM10-mediated cleavage of TNF- $\alpha$ and epidermal growth factor. J. Immunol. 2008, 181, 7002-7013. [CrossRef] [PubMed]

44. Horiuchi, K.; Le Gall, S.; Schulte, M.; Yamaguchi, T.; Reiss, K.; Murphy, G.; Toyama, Y.; Hartmann, D.; Saftig, P.; Blobel, C.P. Substrate Selectivity of Epidermal Growth Factor-Receptor Ligand Sheddases and their Regulation by Phorbol Esters and Calcium Influx. Mol. Boil. Cell 2007, 18, 176-188. [CrossRef] [PubMed]

45. Zhao, D.; Gu, M.Y.; Zhang, L.J.; Jeon, H.J.; Cho, Y.B.; Yang, H.O. 7-Deoxy-trans-dihydronarciclasine isolated from Lycoris chejuensis inhibits neuroinflammation in experimental models. J. Agric. Food Chem. 2019, 67, 9796-9804. [CrossRef] [PubMed]

46. Karthick, C.; Periyasamy, S.; Jayachandran, K.S.; Anusuyadevi, M. Intrahippocampal Administration of Ibotenic Acid Induced Cholinergic Dysfunction via NR2A/NR2B Expression: Implications of Resveratrol against Alzheimer Disease Pathophysiology. Front. Mol. Neurosci. 2016, 9, 555. [CrossRef]

47. Sathya, M.; Moorthi, P.; Premkumar, P.; Kandasamy, M.; Jayachandran, K.S.; Anusuyadevi, M. Resveratrol Intervenes Cholesterol- and Isoprenoid-Mediated Amyloidogenic Processing of A $\beta P P$ in Familial Alzheimer's Disease. J. Alzheimer's Dis. 2017, 60, S3-S23. [CrossRef] 
48. Menon, V.P.; Sudheer, A.R. Antioxidant and anti-inflammatory properties of curcumin. Kidney Dev. Dis. 2007, 595, 105-125.

49. Narasingappa, R.B.; Javagal, M.R.; Pullabhatla, S.; Htoo, H.H.; Rao, J.K.; Hernandez, J.-F.; Govitrapong, P.; Vincent, B. Corrigendum to "Activation of $\alpha$-secretase by curcumin-aminoacid conjugates" [Biochem. Biophys. Res. Commun. 424 (2012) 691-696]. Biochem. Biophys. Res. Commun. 2012, 426, 665. [CrossRef]

50. Tippmann, F.; Hundt, J.; Schneider, A.; Endres, K.; Fahrenholz, F. Up-regulation of the alpha-secretase ADAM10 by retinoic acid receptors and acitretin. FASEB J. 2009, 23, 1643-1654. [CrossRef]

51. Endres, K.; Fahrenholz, F.; Lotz, J.; Hiemke, C.; Teipel, S.; Lieb, K.; Tuscher, O.; Fellgiebel, A. Increased CSFAPPs-alpha levels in patients with Alzheimer disease treated with acitretin. Neurology 2014, 83, 1930-1935. [CrossRef] [PubMed]

52. Brummer, T.; Müller, S.A.; Pan-Montojo, F.; Yoshida, F.; Fellgiebel, A.; Tomita, T.; Endres, K.; Lichtenthaler, S.F. $\mathrm{Nr}$ CAM is a marker for substrate-selective activation of ADAM 10 in Alzheimer's disease. EMBO Mol. Med. 2019, 11, e9695. [CrossRef] [PubMed]

53. Aragão, A.Z.B.; Nogueira, M.L.C.; Granato, D.C.; Simabuco, F.M.; Honorato, R.V.; Hoffman, Z.; Yokoo, S.; Laurindo, F.R.M.; Squina, F.M.; Zeri, A.C.M.; et al. Identification of Novel Interaction between ADAM17 (a Disintegrin and Metalloprotease 17) and Thioredoxin-1. J. Boil. Chem. 2012, 287, 43071-43082. [CrossRef] [PubMed]

54. Peiretti, F.; Deprez-Beauclair, P.; Bonardo, B.; Aubert, H.; Juhan-Vague, I.; Nalbone, G. Identification of SAP97 as an intracellular binding partner of TACE. J. Cell Sci. 2003, 116, 1949-1957. [CrossRef]

Sample Availability: Samples of the compounds are not available from the authors.

(C) 2020 by the authors. Licensee MDPI, Basel, Switzerland. This article is an open access article distributed under the terms and conditions of the Creative Commons Attribution (CC BY) license (http://creativecommons.org/licenses/by/4.0/). 